\title{
Reducing congestion in urban transport by using intermodal transport solutions
}

\author{
N. Brnjac, D. Badanjak \& D. Babić \\ Faculty of Traffic and Transport Sciences, University of Zagreb, Croatia
}

\begin{abstract}
The impact of freight transport on the economy, society and environment has been defined and recognized as an essential element of the European integrations. The increase in the freight transport share has also raised the density of traffic on the urban roads, which in turn raised the problem of traffic flows in the cities, congestion, traffic sustainability and environmental pollution. The past research related to solving the congestion problem in the cities was based on the tendencies to improve the entire transport system. One of the ways is to shift a certain volume of freight from road to other transport branches, which results in the reduction of the number of heavy freight vehicles on the roads and reduction of the adverse impact, i.e. use of intermodal transport which is more environmentally friendly and influences the increase of longevity and organization of urban and suburban traffic. Arguments supporting the mentioned hypotheses include the following. Interoperability as the basic precondition for the development of combined transport can be technical, functional, and market-oriented. Interoperability insures the continuous flow of freight through the entire transport chain, and easier and faster transport of freight and people through the urban areas. Traffic infrastructure has to support the need for different modes of transport; rail transport, road transport and water transport.

Successful operation of combined transport (neutral to the mode of transport) requires the management of the entire transport chain (logistics), freight control, so that freight can be tracked at any moment, as well as the freight safety in the transport chain.

Keywords: intermodal transport, urban transport, logistics, intermodal terminal, congestion, safety, traffic flow, freight transport.
\end{abstract}




\section{Introduction}

Traffic in the cities is conditioned by several crucial factors ranging from the traffic intensity to ecological impacts. The traffic in big or mid-sized cities (such as Zagreb) is growing from year to year thus creating increasing load on a practically unchanged area.

The cities accommodate all the modes of traffic and demands for traffic: land, air, and water.

Precisely because of different transport modes in individual cities in the majority of cases there is the complex problem of solving jams and congestion, which, apart from exclusively traffic parameters, needs to take into consideration also different social and environmental factors with the aim of achieving a satisfactory solution. Surface traffic in cities consists of railway and road traffic, and in the total volume of traffic, road traffic has much greater share than railway traffic.

Modern business operation understands among other things also high share of different forms of transport services, in which an important role belongs to the very transport means. With the increase in the volume of commercial activities there is an increase also in the number of transport means, as well as the volume of transport freight.

The traffic in big cities today is facing two conflicting requirements: on the one hand there is constant tendency for development and increase in the production of goods and services which is to realize the highest possible living standard of the citizens, while on the other hand the citizens want the cleanest possible environment, low noise, safer living conditions in the cities, etc. The increase of industrial production necessarily creates larger amounts of goods that need to be transported which brings about the increase in traffic. In some countries of the European Union road traffic is so dense that the tendency is to shift as much freight as possible from road to railway traffic, and where possible to transport on inland waterways. In this way the tendency is to compensate for constant increase in the demand for the transport of goods. The objective of this work is to analyze the problems related to congestion resulting from insufficient usage of intermodal technologies in urban traffic.

\section{Significance of urban freight transport and advantages of using intermodal transport system}

Currently in Europe $75 \%$ of the population is living in urban areas which leads to a high potential of freight transportation in cities. Freight transportation has a share of about $10 \%$. The share of pick-up and delivery operations on the door-todoor cost is in combined transport about 40\% [1]. Problems of urban transportation in cities are various, from infrastructure (narrow roads), environmental, to the fact that urban freight transport is mainly the distribution of goods at the end of the transport chain and the loads are small which leads to many trips. 
In the urban area of Bremen, Germany, more than 500 tons of fuel are consumed daily for traffic both of freight and passengers. This leads to listed emissions of air pollutants [2]:

$\begin{array}{ll}\text { Carbon monoxides } & 34 \text { to/day } \\ \text { Particles } & 0.16 \text { to/day } \\ \text { NOx } & 18 \text { to/day } \\ \text { CH } & 8 \text { to/day }\end{array}$

Transport systems have always been designed according to geographical conditions as well as the demand for the transportation which was determined by the quantity of goods and service quality. Nowadays, the environmental issue plays a very important role in the transport system design at a public level and it is here that the intermodal transport may show its importance. Intermodal transportation represents a movement of goods using more than one means of transportation. The most common intermodal arrangement is for goods to be moved by truck at their origin, transferred to rail for the long haul between regions, and transferred again to truck near their destination [3].

According to Churchman the systemic approach is considered as the most demanding system in analyzing intermodal transport system, but only when the fact is fully accepted that current European intermodal traffic system still does not qualify completely according to Churchman systemic definition [4]. $\mathrm{He}$ defines five basic system aspects: objective, environment (factors that influence the system but cannot be influenced within the system itself), resources (factors which influence the system but can be influenced from within the system itself), components (components are closely connected with resources and have at least one resource each whereas each resource belongs to the component) and in the end, system management.

The basic effects of intermodal co-ordination include [5]:

- reduction in the number of journeys made by the road cargo vehicles in long-distance traffic, increased number of journeys in inter-terminal traffic (railway) leading to environmental macro-suitability,

- the reduction of the share of heavy cargo vehicles on the roads results in such a structure of vehicles on the roads that at the same mean speed the capacity of traffic routes increases (the effect of "capacity release"),

In relation to the existing transport technologies, the intermodal transport has the following advantages:

- speed,

- accessibility,

- availability,

- reliability,

- security,

- $\quad$ sustainability,

- transparency,

- and the end-user orientation. 
Intermodal transport also enables more efficient usage of the existing infrastructure with reduced negative impacts on the environment. The past research show that within the frame of the European Community up to the year 2020 almost 40 per cent of freight transport will be in the form of intermodal transport. A necessary precondition to achieve the mentioned is the optimization of traffic flows within city centres.

\section{Analysis of urban transport of EU with the case study of the city of Zagreb}

Transport by trucks is the basis of the total traffic service in Croatia and Europe. Trucks transport various types of freight and goods, for a very wide range of customers: from small individual customers to the biggest companies in some countries and regions. Wide use of trucks is first of all a consequence of simplicity and availability of truck transport, but the door-to-door delivery should be mentioned here.

The study refers to the Zagreb region (the capital of Croatia) which has about a million inhabitants. The Zagreb region and the City of Zagreb belong to the economically most developed regions in the Republic of Croatia. Regarding the concentration of the inhabitants and the intense economic activity, there is a large number of passenger, light and heavy-duty vehicles concentrated in the Zagreb region [6].

The level of motorization in Zagreb is relatively high and ranges around 220 automobiles per 1000 inhabitants. The most of these cars are in private ownership.

The consequence of such concentration of vehicles, as well as other factors, is the low throughput capacity of traffic in the urban area, with the average speed of about $20 \mathrm{~km} / \mathrm{h}$. The presence of heavy-duty vehicles during peak hours additionally burdens the traffic network and slows down the traffic.

A special problem due to such large number of vehicles is the shortage of parking spaces, not only in the strict city centre, but also in other residential areas outside the very city centre. These areas also suffer from the problem of parking of heavy-duty vehicles.

\subsection{Examples of implementing parking measures on urban areas and procedures of restricting and supporting truck transport}

Here are some of the procedures of parking measures:

- freeing the parking areas in the residential zones for passenger cars;

- reduction of noise and exhaust gases generated by heavy-duty vehicles;

- $\quad$ increase of pedestrian safety (especially children) in residential areas.

Three basic types of procedures relating to regulation of truck transport need to be distinguished:

- Measures that restrict truck transport;

- Measures that are "neutral" towards truck transport;

- Measures that stimulate and regulate truck transport. 
The type of measures implemented in certain areas depends first of all on the geographic and economic characteristics and interests of a certain urban district. For instance, the most commonly implemented measure that stimulates truck transport has been observed in the port cities and cities with developed industry. In big urban zones the system of measures may be opposed.

In New York, the truck transport is restricted within the city area, whereas the ports in New Jersey and New York, on the contrary, stimulate truck transport Also, proposing and implementation of measures that regulate truck transport is more frequent in those areas in which the decision-making and design system included the economic subjects related to the transport activity (carriers or industrial and trading companies).

Procedures that restrict truck transport are defined as a series of measures with the objective of protecting certain city areas, roads or traffic routes against traffic of heavy-duty vehicles. The success of such measures depends mostly on the level at which these measures have achieved their goal [6].

The usual approach to truck transport management consists of regulations that ban access of heavy-duty vehicles to certain city zones, roads, etc. Most frequently the ban on traffic refers to residential areas and streets that pass through them, even in cases when this refers to busy and important city streets. Less common procedures, that are mainly even more restricting, consist of the systems that force the truck driver to request in advance a permit for passing through a certain area by truck, at an exactly determined time slot. Usually the request for such a permit is accompanied by the data on freight, destination and selected route. Such procedures are very selective since a certain time is necessary for the permit to be issued.

Measures that support truck transport in certain areas have the objective to improve, optimize or maximize the possibilities of heavy-duty vehicle operation. In principle, such a system of measures is implemented in the areas that are aware of the importance of enhancing local economy and industry, in which case the transport of goods play a vital role.

In such a concept the decision-making system usually includes also the representatives of the transport companies, and they become then a very important factor in creating the traffic policy in a certain area.

Other methods used in the cities to improve the traffic of heavy-duty vehicles refer to the study of the carriers' needs, various improvements and shortening of paths through urban zones, building of the nodes for combined transport, etc.

The characteristics of the cities that implement the measures for supporting truck transport are also cities with relatively big industry, port cities, cities with big flows of goods - hubs.

Cities that implement neutral measures have the following characteristics [6]:

- Cities that are not big industrial nor commercial centres;

- Cities with conflict of interest that support and restrict truck transport;

- Cities that tend to develop advanced transport technologies. 
Regarding the increasing number of vehicles in the cities, there is the problem of systemic approach to solving the problem of the traffic by delivery and heavyduty vehicles in the wider city area and the strict city centre.

Due to their dimensions and limited manoeuvring capabilities, heavy-duty vehicles are not suitable for the traffic in the cities, especially in the urban area itself. The consequences of the truck transport are traffic congestion or slowed down transport at certain points, and there is also the possibility of traffic accidents, which often have very serious consequences owing to the vehicle characteristics.

Road transport of goods in Croatia has the highest share regarding the volume of goods carried. In 2005 as many as 59,000 thousand tons of goods were transported by road, which, compared to the year 2000 represents an increase of almost 11 times. Also, in comparison with the pre-war indicators, road transport marked an impressive growth of physical indicators. Regarding volume of goods, the majority of road transports in Croatia refer to internal traffic, i.e. almost 51,000 thousand tons. The rest refers to international goods exchange, whereas goods transport by roads for third parties regarding volume is almost negligible. During 2005 a total of 9,328 million ton-kilometres were realized in road transport.

The measures that are used to regulate truck transport in urban areas consist of approximately some 15 elements which in various ways affect traffic of heavy-duty vehicles. Most often these elements are relatively loosely linked so that one cannot speak of an integral and consequent system of truck transport regulation measures. One of the elements which is treated here and which tends to regulate truck transport is the following:

- Intermodal transport: stimulating shift of goods transport by trucks to rail or river transport where possible.

\section{Intermodal impact on urban transportation}

The application of road-rail transport modes contains essential environmental effects over unimodal transport mode. However, negative impacts such as noise and congestion can be somewhat higher. This refers, though, only to those citizens who live in the close vicinity of the terminal.

Transport chains can be organised like single-step transport chain and multistep chain. Multi-step transport chain is organisation of transport process between supply and reception points with change of means of transportation, or intermodal transportation (no change of loading unit). Further more combined transportation is divided on accompanied (loading of whole vehicles or parts of it roll-on-roll-off transport, float-on-float-off transport) and container (loading of loading units, containers).

Intermodal impact on urban traffic could be explained as shown in Figure 1.

The concept of constructing intermodal terminals is usually such that the terminals are constructed on the outskirts of the cities and they receive freight whose destination is in the considered city. After that the goods are further 


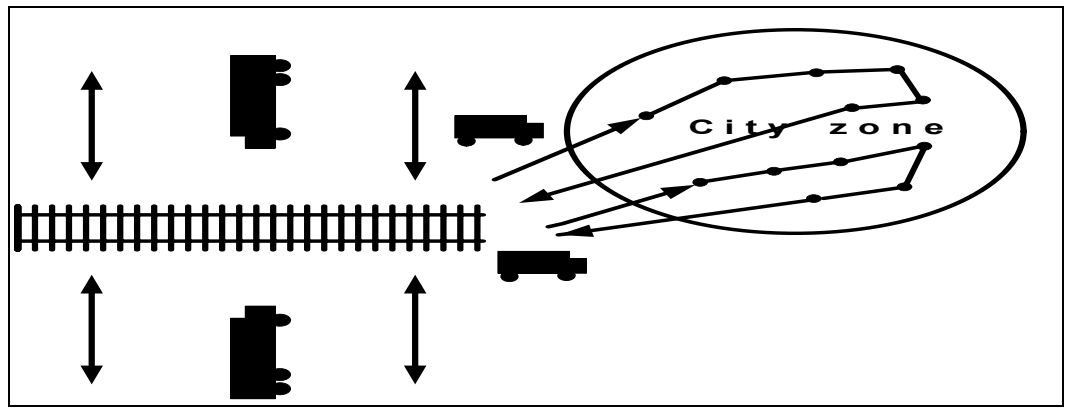

Figure 1: Example of solving the problem of urban freight transport with intermodal terminals.

distributed to the end user in the city area by means of smaller trucks or delivery vans, or, according to another concept, by using special delivery vehicles, that apart from supply can be used for some other purposes as well.

Such delivery vehicles should be environmentally friendly, produce low level of noise and meet all the other requirements stipulated by the city authorities.

This approach to supply makes it possible, according to some research, to reduce the traffic by trucks in the city area between 30 and $50 \%$.

Today, terminals (IT) are usually located near the main bus and railway stations in the very centre of the cities. Intermodal terminals placed on a rim of the cities allow shorter local road haulage as well as smaller local effects, while trucks and lorries have to cross the city centre to reach a correct terminal. With usage of rail transportation in cities the average distance to a terminal could be decreased.

\section{Conclusion}

According to past experience, the consequences of the movement of heavy-duty vehicles through urban areas are the following:

- $\quad$ increase of the permitted level of noise;

- increased air pollution (according to some medical research air pollution caused by Diesel engine exhaust gases includes also an increased volume of soot particles which cause serious diseases of the respiratory vascular systems);

- larger number of conflicting situations - traffic accidents involving heavy-duty vehicles usually have serious consequences: big material damage, serious injuries and fatalities. There is also the risk of heavyduty vehicle collisions with pedestrians crossing the road or walking along.

- $\quad$ in spite of decisions, heavy-duty vehicles park in the areas that are not intended for that purpose. When such areas are in the vicinity of residential objects, the impact of heavy-duty vehicles on the environment is multiple: increased level of noise, increased emission of 
exhaust gases, greater possibility of conflicting situations (traffic accidents) caused by the movement of heavy-duty vehicles through the residential areas.

As conclusion the following may be claimed:

- the use and development of as many intermodal terminals as possible at the city outskirts reduces all the abovementioned consequences of heavy-duty vehicle operation in the cities, because in this way the transport of heavy-duty vehicles is eliminated from the city roads.

\section{References}

[1] IMPULSE, Operation Forms for the Network Modes, IN -95-SC.001, European Commission, Bruxelles 1996

[2] Inner urban freight transport and city logistics, European Commission, Bruxelles 2003

[3] Benchmarking Intermodal Freight Transport, OECD, 2002.

[4] Woxenius, J.: Development of small-scale intermodal freight transportation in a systems context, 1998.

[5] Brnjac, N., Badanjak, D., Jenić, V.: Planning huckepack technology advanced transport technologies in EU, Transportation Science and Technology, Elsevier, 2007.

[6] Truck solutions in City Zagreb, Faculty of Transport and Traffic Sciences, 2006

[7] Group of authors: Trends in Heavy Truck Traffic Management Study, Cambridge Systematics, inc., Fort Lauderdale, Florida, 2005

[8] Peter Loffler: City logistics a contribution to Sustainable Development? World Transport Policy \& Practice, 5/2 (1999), Bruxelles, 1999 